Int. J. Electrochem. Sci., 15 (2020) $3315-3326$

\title{
In situ Monitoring of pH at the Electrode|Electrolyte Interface During the Anodic Dissolution of Iron in Acidic Solutions
}

\author{
Weiyan Ni, Yu shao, Jiaojiao Qi, Boyu Yuan, Liang Li*, Chao Wang * \\ Jiangsu Key Laboratory of Green Synthetic Chemistry for Functional Materials, School of Chemistry \\ \& Materials Science, Jiangsu Normal University, Xuzhou, 221116, China \\ "E-mail: 1il@jsnu.edu.cn(Liang Li), wangc@jsnu.edu.cn(Chao Wang)
}

doi: $10.20964 / 2020.04 .47$

Received: 2 December 2019 / Accepted: 20 Janaury 2020 / Published: 10 March 2020

The anodic dissolution of iron in $\mathrm{H}_{2} \mathrm{SO}_{4}$ and $\mathrm{HNO}_{3}$ solutions was studied by using scanning electrochemical microscopy (SECM) with a Pt ultramicroelectrode modified with polyaniline and by in situ monitoring of $\mathrm{pH}$ at the electrode|electrolyte interface. In each acidic solution, $\mathrm{pH}$ at the interface changed periodically during the observed current oscillations of iron, indicating that the oscillatory mechanism had some connection with $\mathrm{pH}$. During the oscillatory processes, there were two layers of the film on the surface of the iron electrode: a loose outer layer $\left(\mathrm{Fe}(\mathrm{OH})_{2}\right.$ and the salt film) and a dense inner layer $\left(\mathrm{Fe}_{3} \mathrm{O}_{4}\right)$. First, the outer layer was formed gradually, and then the inner layer was formed under the protection of the outer layer. With the back diffusion of $\mathrm{H}^{+}$, the outer layer was dissolved gradually, indicating that the outer layer was mainly the $\mathrm{Fe}(\mathrm{OH})_{2}$ film; however, the inner layer was broken immediately after the dissolution of the outer layer. The results showed that $\mathrm{pH}$ of the solution played a key role and that the anions played a minor role during the current oscillations. It was reasonable to deduce that the oscillations were mainly caused by a periodic formation and dissolution of the oxide film. Furthermore, the salt film played a minor role even though the acid concentrations were high.

Keywords: current oscillations; $\mathrm{pH}$; oxide film; iron; acid.

\section{$\underline{\text { FULL TEXT }}$}

(C) 2020 The Authors. Published by ESG (www.electrochemsci.org). This article is an open access article distributed under the terms and conditions of the Creative Commons Attribution license (http://creativecommons.org/licenses/by/4.0/). 